\title{
ITINERAÇÕES E MALHAS PARA PENSAR OS ITINERÁRIOS DE CUIDADO. A PROPÓSITO DE TIM INGOLD*
}

A obra de Tim Ingold é complexa e está em processo de construção. Desafia os limites do campo da antropologia e as suas divisões internas. Por isso mesmo, em certo sentido, é revolucionária, mas essas mesmas características permitem inseri-la em uma linha de pensamento que já tem certa "tradição". Pela vastidão e complexidade da obra é quase impossível dar conta em um artigo, porém o meu objetivo aqui é uma tentativa de expor algumas de suas observações e refletir sobre como podemos nos valer delas para visitar antigas questões de pesquisa em campos nos quais o próprio Ingold não se debruçou. Se este objetivo pode parecer a princípio ousado, acredito, no entanto, que está sugerido nas linhas de Being alive (20II: 75), nas quais Ingold diz que o pensamento animista tem que nos servir para questionar e repensar a cosmologia ocidental:

Se a ciência é para ser uma prática de conhecimento coerente, deve ser reconstruída na base da abertura ao invés de encerramento, e do compromisso em vez de desprendimento. E isto significa recuperar a sensação de espanto que é tão conspícua pela sua ausência do trabalho científico contemporâneo. O conhecimento deve ser religado com o ser, a epistemologia com a ontologia, o pensamento com a vida. Assim, nossa reflexão sobre animismo indígena nos levou a propor a reanimação da nossa própria tradição de pensamento chamada "Ocidental".

Este é o esquema geral deste texto. A pergunta que me guia ao ler Ingold é: será que podemos usar as ideias que provêm de outros contextos de 
pesquisa para pensar os temas que me interessam? Daí usar as reflexões de Tim Ingold para explorar os itinerários de cuidados com a saúde.

Basicamente, meu caminhar pela obra de Ingold vai partir das concepções de obviação e da transversalidade dos campos para chegar à de itineração e dos emaranhados de linhas de vida. Usarei estas noções - itineração e malha - para repensar a de itinerários terapêuticos.

\section{A ANTROPOLOGIA DESDE AS MARGENS}

Quando no início deste texto propus que Ingold se inseria numa certa "tradição" não cristalizada, estava me referindo ao desenvolvimento de um pensamento relacional. Essa característica não é novidade; na verdade, muitos antropólogos defendem uma perspectiva relacional. Talvez não seja possível outra antropologia. Mas o que considero interessante é associar esse pensamento relacional a uma busca por transcender os limites dos campos disciplinares. O pensamento relacional em Ingold evoca uma visão "ecológica" que leva necessariamente a associar duas perspectivas: biológica e antropológica. Essa associação se reflete na proposição de que "a pessoa é o organismo" (Ingold, 2000: 3), ou naquela do organismo-no-seu-entorno, que fundamenta a perspectiva do habitar.

Também se poderia dizer que não é novidade, ou que outros antropólogos já tentaram uma perspectiva que atravessasse os campos disciplinares da biologia e da antropologia, ou os enclaves da natureza e da cultura. E é por isso que me interessa.

Considero que existe uma relação direta de realimentação entre a busca dessa transversalidade e certa marginalidade, ou estar à margem. Não acho que seja casualidade que Ingold faça repetidas vezes referência a Gregory Bateson como uma figura que o influenciou. A proposta de uma "ecologia da vida", que aparece desde a introdução de The perception of the environment, é devedora de Bateson, como o próprio Ingold explicita (Ingold, 2000: 9); mais ainda, Ingold diz que Bateson foi "um grande desmontador de oposições, entre razão e emoção, interno e externo, mente e corpo" (2000: I6). ${ }^{\mathrm{I}}$ Também em Being alive (Ingold, 20I : 86), Bateson será retomado para ajudar a fundamentar a noção de malha, a partir da ideia de mente. É sabido que Bateson foi uma figura marginal na antropologia; isso fica demonstrado no percurso da sua obra que, começando na antropologia inglesa pela mão de Haddon e passando pela psiquiatria, pela teoria da comunicação e pela etologia, vai terminar no estudo do sagrado como um modo de conhecimento (Bateson, I989). É uma obra marcada pela liberdade e criatividade das margens e pela transversalidade dos campos. Bateson teve uma formação em biologia (filho de William Bateson, geneticista famoso no início do século XX) e posteriormente se interessa pela antropologia. Talvez seja derivada dessa formação que Bateson 
conseguiu transcender a oposição entre natureza e cultura para alcançar os padrões que as conectam (Bateson, I982).

Essa percepção da marginalidade de Bateson, que ele próprio enxergava (Bateson, I989; Harries-Jones, I995), também foi explicitada no texto de Otávio Velho, De Bateson a Ingold (Velho, 200I). Nesse texto, Velho diz que "novos ventos" estariam soprando na antropologia (Velho, 200I: I34). Ventos dos quais o livro de Ingold, The perception of the environment, seria um exemplo e que poriam em questão a separação entre natureza e cultura. Mas também me interessa mencionar aqui uma possível marginalidade no próprio Ingold, como revela Otávio Velho: "Quem sabe não se poderia agregar Ingold a esta lista de autores intempestivos e excêntricos? Pelo menos eu já o vi reclamar de não ser lido por seus colegas britânicos, o que pode representar uma motivação para esse esforço de aproximação" (Velho, 2013: I09). ${ }^{2}$ Poderíamos nos perguntar se essa excentricidade, de que fala Otávio Velho, não estaria em uma relação de realimentação com a falta de leituras de seus colegas ingleses. Falta de leitura que se associa com a novidade e a direção centrífuga das ideias de Ingold. ${ }^{3}$

Se Bateson tinha a sensação de que a antropologia o tinha abandonado, pelo rumo divergente de ambos, Ingold segue outro caminho, que é modificar a antropologia. Se o autor já vinha dando numerosas pistas, esse projeto fica explícito no início do livro Being alive (Ingold, 20II) e, posteriormente, em Making (Ingold, 2013). No primeiro, a clave está em reinserir a vida no pensamento antropológico; é necessário realocar a vida porque a antropologia a perdeu quando se preocupou demais com "padrões, códigos, estruturas, ou sistemas, várias vezes definidos como genéticos ou culturais, naturais ou sociais" (Ingold, 20II: 3). A proposta de Ingold é conceber uma antropologia através de linhas de vida, de linhas de crescimento, como um processo em aberto no qual o homem não pode ser pensado como separado do ambiente; ambos, homem e ambiente, estão em um processo de desenvolvimento e são produto dele.

No segundo livro, Making, a proposta se amplia para uma conjunção entre antropologia, arqueologia, arte e arquitetura. O que permitiria fazer essa associação é que essas quatro disciplinas seriam guiadas por "modos de pensar através do fazer" (Ingold, 20I3: xi). Ingold propõe uma disciplina em que se cria um conhecimento "de dentro", por compartilhar o fazer, e, nesse processo, "todo o terreno do conhecimento é reconfigurado. Em vez de superfícies territoriais segmentadas em domínios, ou campos de estudos, temos algo mais semelhante a cordas, trançadas com os correspondentes fios ou linhas de interesse" (Ingold, 2013: I2).

Essa reconfiguração dos campos permite que Ingold se defina como antropólogo sem qualificativos de social, biólogo ou arqueólogo, mas "só um antropólogo" (Ingold, 20II: xi). Essa negação à qualificação da antropologia 
traz um interesse em redefinir a disciplina como "uma investigação sobre as condições e potencialidades da vida humana no mundo em que todos habitamos" (Ingold, 20I2: 35). Para isto deveríamos definir como a tarefa da antropologia "seguir o que está acontecendo, rastrear as múltiplas trilhas das coisas em seu fazer coisas, onde quer que elas nos guiem” (Ingold, 2012: 48).

A proposta do Ingold implica não só uma nova definição da antropologia, mas também uma redefinição do que é uma disciplina acadêmica. Para ele, historicamente entendemos cada disciplina acadêmica como um território particular, demarcado sobre a superfície da mente, do mesmo modo como os fenômenos com os quais trata são demarcados na superfície da terra. Entretanto, se mudássemos esse entendimento, diz Ingold, "todo o terreno do conhecimento apareceria não como uma superfície segmentada em domínios ou campos de estudos, mas como uma emaranhada malha de sendas em curso ou linhas de interesse" (Ingold, 2012: 48).

Nessa mesma argumentação Ingold mostra a sua desconfiança sobre a "interdisciplina", não para defender que os cientistas têm que se manter isolados em seus mundos acadêmicos, mas porque desconfia do "inter" ou "entre" que enfatiza a concepção de mundos fechados, que podem ser relacionados por meio de pontes entre os domínios. A interdisciplina contribuiria para formar as barreiras que diz atravessar (Ingold, 20I 2: 49).

Neste ponto já posso encaminhar o meu argumento para o primeiro movimento de diluição dos limites disciplinares. Nesse movimento, os domínios em questão são a biologia e a antropologia, ou natureza e cultura. ${ }^{4}$ Esse questionamento dos limites disciplinares resulta interessante para tratar de algumas das questões que têm sido discutidas na antropologia da saúde e da doença, na antropologia do corpo e, mais recentemente, na antropologia das emoções.

\section{A OBVIAÇÃO DAS MARGENS}

Nesse processo, Ingold vai definir o que ele chama de perspectiva da obviação, em contraposição a uma perspectiva da complementaridade. Pela sua centralidade a questão aparece em vários momentos da obra, entretanto fica explícita em dois textos: "Da complementaridade à obviação. Dissolvendo os limites entre antropologia biológica e social, arqueologia e psicologia" (Ingold, 200I), e "Três em um: como dissolver as distinções entre mente, corpo e cultura" (Ingold, 2008). A questão também aparece prefigurada em um texto que integra a coletânea The perception of the environment (Ingold, 2000), mas que originalmente foi publicado em I995, denominado "Gente como nós. O conceito de humanos anatomicamente modernos". Nele, Ingold se pergunta "Por que o Cro-Magnon não andava de bicicleta?” A resposta óbvia, diz Ingold, é que não havia bicicleta. Mas essa pergunta, que parece uma piada, esconde uma questão relevante: que o Cro-Magnon não andasse de bicicleta porque 
não havia em seu tempo implica a ideia de que ele tinha as possibilidades anatômicas para tal, mas não a cultura. Em outras palavras: biologicamente era igual a nós, mas culturalmente diferente. O argumento de Ingold nesse texto busca pôr em dúvida essa assertiva, por considerar que, se o nosso corpo emerge da atividade do viver, essa atividade afeta o modo como o corpo se constitui. A ideia de andar de bicicleta tem semelhança com o processo de caminhar. Ingold afirma que não tem nada natural no andar e, nessa argumentação, dirige a discussão para o trabalho sobre as técnicas corporais de Marcel Mauss (2003).

Nesse texto, Mauss sustenta que andar seria uma técnica adquirida culturalmente e que essas técnicas são alcançadas pela imitação prestigiosa. Assim, o corpo seria "o primeiro e mais natural instrumento do homem" (Mauss, 2003: 407). Para dar conta desses fenômenos "difusos" teríamos, segundo Mauss, que lançar mão da noção de "homem total", fazendo intervir uma "tríplice consideração em vez de uma única" (Mauss, 2003: 405). Essa mesma perspectiva é encontrada em outros dois textos-chave de Mauss que nos permitem entender a construção da pessoa. Estou me referindo ao texto sobre o efeito físico da ideia de morte sugerida pela coletividade (Mauss, 2003b) e ao texto sobre a manifestação dos sentimentos nos rituais funerários (Mauss, 200I). No primeiro, Mauss explica por que indivíduos que não têm nenhum distúrbio psíquico adoecem e morrem recorrendo a ideias e sentimentos de origem coletiva; o individuo acredita-se enfeitiçado e morre por essa razão. Mas - e isso é o que interessa para a nossa discussão -, na tentativa de explicar o fenômeno, diz que se trata de um gênero de fatos

em que a natureza social reencontra muito diretamente a natureza biológica do homem. Esse medo pânico que desorganiza tudo na consciência [...] desorganiza, sobretudo, a própria vida. O elo psicológico é visível, sólido: a consciência [...]. A consideração do psíquico, ou melhor, do psíquico orgânico, é insuficiente aqui [...] a consideração do social é necessária (Mauss, 2003: 364).

Podemos extrapolar essa afirmação sobre os efeitos das representações coletivas sobre o físico do homem para a perspectiva maussiana sobre as emoções, quando, na sua análise sobre o choro nos rituais funerários, escreve que a manifestação das emoções trata de uma linguagem simbólica que configura um terreno "sobre o qual psicólogos, fisiólogos e sociólogos podem e devem encontrar-se" (Mauss, 2001: 332).

Para entender esses fenômenos difusos que interessavam a Mauss é necessário um deslocamento de perspectiva. Para responder à pergunta de Ingold, de por que o Cro-Magnon não andava de bicicleta, temos que produzir o mesmo deslocamento, a fim de, dessa forma, reposicionar o diálogo entre biólogos, antropólogos e psicólogos. A solução ingoldiana para esta pergunta é sair da oposição e pensar em outra perspectiva "que feche a brecha entre artes e humanidades, por um lado, a as ciências naturais, do outro" (Ingold, 
200I: 255). Um modo de fechar essa brecha é o que Ingold fará nos dois textos aos quais me referi na abertura desta seção.

Embora no título do texto de 200I, "Da Complementaridade à obviação", apareçam as disciplinas a dissolver (antropologia biológica e social, arqueologia e psicologia) e, no título do segundo, "Três em um", os conceitos em que cada disciplina se baseou (mente, corpo e cultura), os dois textos apresentam um percurso semelhante tentando responder à pergunta a respeito de quais são as condições de possibilidade da vida humana, ou, para expressá-la de outro modo, o que é um ser humano? Responder a isto necessariamente envolve o diálogo entre vários campos.

Segundo Ingold, a perspectiva da complementaridade se constitui por uma aliança entre biologia, psicologia e antropologia; cada uma destas disciplinas vai contribuir com um paradigma e com conceitos associados: neodarwinismo, psicologia cognitiva e teoria cultural, respectivamente. Essa aliança se fundamenta em dois pressupostos: o primeiro é a proposição que a existência humana é realizada entre duas clivagens diferentes: por um lado, entre o mundo social e o mundo natural, e entre o individuo e o seu entorno; o segundo pressuposto é que, embora cada uma dessas disciplinas trate de uma dimensão do ser e produza uma construção parcial, é viável elaborar um relato totalizante que dê conta do sujeito no mundo.

Assim, o poder dessa aliança reside na promessa que, associando os três constructos disciplinares, é "possível um relato sintético da totalidade. Esta síntese é caracteristicamente denotada pelos termos híbridos tais como biossocial, psicocultural, ou inclusive biopsicocultural" (Ingold, 2001: 255).5

Cada uma das disciplinas formadoras da aliança contribuiria com conceito-chave que permitiriam reconstruir a totalidade; assim, a biologia evolutiva falará de como, no processo evolutivo, entram em jogo o genótipo, os genes, na sua relação com o ambiente, constituindo o fenótipo e, a partir deste jogo, poderíamos conhecer a "natureza humana". O que evolui são os genes, na sua relação com o ambiente; mas, Ingold se pergunta por que o ambiente deve relacionar-se com os genes e não com qualquer outro componente do organismo? (Ingold, 2008: 7).

A partir dessa perspectiva, tem que ser possível dizer o que é um ser humano, para além do ambiente, e das condições do desenvolvimento. Assim - e voltando à questão das técnicas corporais de Mauss -, dessa perspectiva pode-se sustentar que a capacidade de andar é universal, como uma capacidade inata, mas os modos de andar seriam particulares de cada contexto cultural. Os modos de andar seriam modificações fenotípicas do genótipo preestabelecido.

A mesma crítica, Ingold faz à psicologia cognitiva, que postula uma estrutura da mente formada por mecanismos cognitivos que deveriam existir antes dos padrões culturais, para que esses sejam transmissíveis, ou para que 
alguma coisa seja aprendida. Ou seja: a proposta se fundamenta na ideia de que, assim como temos um corpo que pode andar, temos um aparelho fonador que permite falar, e uma mente que tem dispositivos que permitem assimilar as representações dos modos de andar e falar determinados idiomas. A questão que Ingold levanta é a respeito de como esses mecanismos se transmitem, o que nos leva à questão do inato e do adquirido e, com ela, ao problema de como "distinguir entre estruturas inatas e adquiridas" (Ingold, 2008: 9). Segundo Ingold, a ciência cognitiva responderia a esta questão com referências imprecisas à genética e à seleção natural, mas o casamento com a biologia evolucionista manifestaria contradições. Se, para os biólogos evolucionistas, o organismo é produto de uma conjunção entre o genótipo e o ambiente, para a ciência cognitiva o organismo teria uma arquitetura mental pré-moldada quando chega ao mundo. O organismo deveria dispor de "programas" integrados ao cérebro para poder funcionar e para que alguma coisa seja aprendida; programas que não poderiam ser produto da experiência, senão precisaríamos de outro programa para processar a experiência, ocasionando uma busca interminável (Ingold, 200I: 270).

Finalmente, Ingold se refere à terceira disciplina que sustenta a perspectiva da complementaridade: a antropologia com a sua teoria cultural. A crítica se direciona novamente para a teoria da cultura associada à antropologia cognitiva; basicamente aponta para a concepção de que a cultura se transmite através de gerações sem depender das situações de sua aplicação prática no mundo: "a informação transmitida culturalmente contém uma especificação para seu comportamento independente do contexto, que consiste no que se descreve como planos, programas, esquemas, representações, receitas, regras e instruções" (Ingold, 2008: Io).

Em contraposição a essa perspectiva, como disse anteriormente, Ingold propõe a da obviação: a base teórica de sustentação vai ser construída a partir da aproximação da biologia do desenvolvimento, da psicologia ecológica e da teoria da prática.

Nessa perspectiva, a cultura, a mente e o corpo se dissolveriam no todo organismo-pessoa. O ser humano seria não um produto do desenho genotípico independente do ambiente, mas a consequência das potencialidades generativas e criativas do sistema de desenvolvimento. Isto é, "um sistema inteiro de relações constituído pela presença do organismo, incluindo os genes num ambiente concreto" (Ingold, 2008: I5). O corolário disso é que não existe uma natureza humana independente dos inúmeros modos que os humanos têm de viver as suas vidas.

Nessa perspectiva, o caminhar e o falar não se adquirem, mas se geram no processo de desenvolvimento. Na verdade, "absolutamente nada se transmite", diz Ingold (2008: 2I). O que, sim, encontramos é um "redescobrimento guiado", isto quer dizer que cada geração mostra o que fazer à geração seguinte. In- 
gold chama esse mostrar de "educar a atenção". A ênfase está colocada não na reprodução, mas na criação continuada. Nesse processo emerge o ser humano como "um centro de consciência e agência, no qual os seus processos têm ressonâncias com os processos do entorno" (Ingold, 2008: 22).

O ponto central do argumento é que, nessa unidade que emerge no processo de desenvolvimento, o organismo-pessoa, não faz sentido separar o corpo do organismo, ou a mente do corpo, ou o coletivo do individual. Deveríamos, assim, falar tanto de corporeidade [embodiment] quanto de mentalização [enmindment], dado que seriam dois modos de descrever o mesmo fenômeno (Ingold, 2000: 170). ${ }^{6}$ Nessa perspectiva ecológica e relacional, já não faria sentido separar nem o organismo da pessoa, nem esse organismo-pessoa do entorno porque o que está em processo de desenvolvimento é a totalidade formada. A perspectiva da obviação compõe o que Ingold chama de um pensamento relacional; consistiria em tratar o "organismo não como uma entidade discreta e pré-programada, mas como um lócus de crescimento e desenvolvimento concreto dentro de um campo contínuo de relações" (Ingold, 2008: 3I).

Até aqui tentei mostrar os desenvolvimentos que levaram Ingold a repensar as relações entre as dimensões constitutivas do sujeito que historicamente eram, e são, separadas nas dimensões biológicas, culturais e psicológicas. Essas separações deram lugar a polêmicas interessantes e ao mesmo tempo problemáticas sobre o estatuto das emoções nas diferentes culturas, por exemplo. Um segundo passo na construção da perspectiva ingoldiana está explícita nos textos mais recentes nos quais se conceitualiza a percepção de ambiente como emaranhados de linhas de vida.

\section{AS MALHAS DE LINHAS DE VIDA}

Há algum tempo venho pesquisando as relações entre médicos e usuários no sistema de atenção primária de saúde; nesse caminho, interessado na experiência terapêutica no programa de saúde da família, fui levado a focar no conceito de rede e, através dele, a entender o sistema de saúde como um conjunto de redes que se interpenetram. Nessa pesquisa falávamos ${ }^{7}$ de rede oficial de saúde, para fazer referência ao sistema, e de como essa rede se relacionava com as que chamávamos de redes intersticiais de saúde, para indicarmos as redes de vizinhança, de terapeutas "alternativos", religiosos ou não (Bonet \& Tavares, 2006; 2007).

Posteriormente, na pesquisa sobre emoções e itinerários de cuidados terapêuticos na rede de Clínicas da Família no Município de Rio de Janeiro, minha atenção se voltou para os percursos, pelos caminhos através dos quais os usuários buscam receber atendimento. ${ }^{8}$ Em outras palavras, fui atraído pela circulação dos usuários pelo sistema; assim, fui ganhando interesse pelos processos; o sistema de saúde passou a ser considerado como um processo. 
Nesses deslocamentos pelo sistema de saúde, os usuários vão estruturando o próprio sistema, o que frequentemente não coincide com a estrutura que os gestores do pensaram para ele. Em outras palavras, ao se movimentarem pelo serviços, os usuários tomam decisões e, com elas, vão construindo uma história. Ao fazer um caminho pelo sistema se constrói uma história. Esses movimentos se realizam no processo de "habitar" o mundo, ou, no nosso caso, "habitar" o sistema de saúde. Ingold sugere que o modo pelo qual andamos no mundo é pautado não por mapas dentro das nossas cabeças, mas por "matrizes de movimentos" que configurariam o que ele chama de "região". Nessas regiões, os lugares não têm uma posição, mas, sim, histórias (Ingold, 2000: 219). Então, quando buscamos e encontramos um caminho, contamos uma história; assim, os lugares são unidos pelas histórias de seus habitantes. Ingold propõe que

o mundo não é pré-montado para ser ocupado pela vida [...] caminhos da vida não são predeterminados como rotas a serem seguidas, mas têm que ser continuamente elaborados sob nova forma. E esses caminhos, longe de serem inscritos sobre a superfície de um mundo inanimado, são os próprios fios a partir dos quais o mundo vivo é tecido (Ingold, 2000: 242).

Para pensar este mundo vivido ao longo do qual nos movimentamos, no livro Being alive (20II), Ingold vai trabalhar a reflexão de que a "vida" está relacionada com o processo de desenvolvimento, que se faz ao longo de linhas de fuga e não de fechamento. Nesse momento, Ingold propõe a noção de malha [meshwork], entendida como um emaranhado de linhas de vida, crescimento e movimento (Ingold, 20II: 63). Nesse emaranhado de linhas de fuga, as linhas não se conectam, mas são linhas ao longo das quais se percebe e se atua. São linhas de vida. O meio onde a vida se faz (o enviroment) é, para Ingold, não uma rede de pontos interconectados, mas um emaranhado de linhas entrelaçadas.

Para Ingold, a ação no mundo não é o resultado de uma agência distribuída em torno da rede, mas, antes, emerge do jogo de forças que é conduzido através das linhas da malha (Ingold, 20II: 92). Usando a teia de aranha como metáfora, Ingold afirma que

a rede não é uma entidade. Ou seja, não é um objeto independente fechado que está definido contra outros objetos com os quais pode então ser justaposto ou unido. É, sim, um pacote ou um tecido de linhas, fortemente unificadas, mas com alguns pontos em aberto, sem conexão, que se agrupam com outras linhas de outros agrupamentos (Ingold, 2011: 91).

Assim, as linhas da teia de aranha, que são produzidas por materiais do próprio corpo da aranha, permitem que ela sinta quando um animal fica preso nela. A teia não é uma coisa diferente da aranha - faz com que ela seja possível; nesse sentido, é a sua condição de possibilidade. A teia é produto do 
movimento da aranha, os fios são feitos à medida que ela trilha o ambiente; são linhas de percepção e ação (Ingold, 2012b: 40).

A ideia-chave de Ingold é que nós nos movemos em um espaço fluido, no qual a nossa atividade, como organismo-pessoa, deve ser entendida como um aspecto do desdobramento do sistema total de relações, composto pela presença corporificada em um meio ambiente específico (Ingold, 20II: 86).9 Assim, a teia e a aranha se produzem mutuamente, conjuntamente. Daí que Ingold desenvolve o esquema de "correspondência" [togetherness], através do qual se podem pensar os modos nos quais as linhas se juntam e se respondem mutuamente (Ingold, 20I2: 47). As linhas de vida são linhas de devir, de maneira que, quando um inseto cai na teia da aranha, esta não liga a aranha ao inseto, mas as linhas dos dois insetos operam um como contraponto do outro (Ingold, 20I2b: 4I).

A partir dessa perspectiva, a ênfase estará não nas formas, que para Ingold constituiria um momento posterior, produto do processo de fechamento das linhas sobre si mesmas, mas nos fluxos, nas linhas de crescimento e vida, emaranhadas ao longo das quais a vida acontece. Já não lhe interessam os objetos autocontidos, mas, sim, observar como esses interagem com o meio, como se estendem para além deles mesmos. Ou, para usar a metáfora dele próprio: como vazam. As coisas vazam (Ingold, 20I2b: 42). Esse processo permanente do extravasar das coisas é o que Ingold chama de trazer as coisas de volta à vida. As coisas estão na vida porque vazam, porque estão no fluxo constante; daí que não lhe interessem as formas que surgem quando se freia o fluxo da vida, quando se freiam os processos.

Essa ênfase nos fluxos está relacionada diretamente com a ideia de movimento "ao longo de", que Ingold chama de flâneur [wayfaring]. Seria não um movimento que busca conectar pontos, mas um movimento que "busca continuar andando" (Ingold, 2012: 46). O flâneur é um movimento de seguir para adiante, de se mover; e nele se encontram os diferentes devires (humanos, animais e outros), que constituem e que se constituem no próprio movimento. O objetivo, no esquema ingoldiano, já não será entender os processos que conectam dois pontos, mas entender o movimento entre um e outro ponto. Nesses diferentes devires, projetam-se linhas ao longo das quais se vive a vida. Por isso que são linhas de vida (Ingold, 20I2: 63).

Um último conceito complementa o de flâneur: é o de itineração. Este é um movimento para frente e que envolve criatividade e improvisação. A itineração não conecta pontos, mas consiste em um sistema aberto de improvisações (porque acontecem no desenrolar da ação) e ao longo da qual a vida é possível. As itinerações não se dão em um mundo em rede que preexiste, mas em uma malha de linhas de vida que se produzem na mesma itineração. Voltando à metáfora da aranha: sua teia é um produto da itineração dela e torna a sua vida possível. A teia é condição de existência da aranha. 


\section{REPENSANDO OS ITINERÁRIOS DE CUIDADOS E OS SISTEMAS DE SAÚDE}

Após esses rápidos e interessados comentários sobre algumas ideias de Ingold, posso retomar o objetivo inicial e propor uma passagem da noção de itinerários terapêuticos para a de itinerações na busca de cuidado. Parece-me óbvia a relação dessa proposta com a minha itineração pela obra do Ingold; a ideia básica que sustenta a proposta é pensar os itinerários como processos abertos, em permanente fluxo, e sujeitos a constantes improvisações criativas dos usuários e dos profissionais envolvidos nos processos cotidianos da vida.

Menos óbvio é o corolário dessa perspectiva com ênfase nos fluxos e nos processos, e que está associado à concepção de malha de Ingold: se os itinerários estão sujeitos a constantes improvisações dos agentes, então não se pode falar de percursos previstos e, portanto, de uma rede que preexista aos movimentos dos agentes, mas de uma malha de linhas que vai sendo construída nos fluxos e nos processos.

A perspectiva sobre os itinerários que estou propondo no presente texto busca explicitar uma associação e contribuir para a compreensão dos modos de circulação dos usuários e dos profissionais pelo sistema de saúde. O conceito de cuidado será entendido como uma categoria situacional e metafórica. Isto quer dizer que tem uma qualidade mais fluida e mais plástica. O fato de ser categoria metaforizada, como defendemos em outro texto (Bonet \& Tavares, 2007), remete ao fato de que, quando os profissionais falam em cuidado, frequentemente estão se referindo a percepções-ações que são diferentes de quando os usuários se referem à categoria de cuidado. Assim, o cuidar do profissional é percebido diferentemente do cuidar da mãe, por exemplo.

De forma complementar a esta característica metaforizada da categoria de cuidado, a perspectiva proposta aqui requer uma visão ampliada do cuidado. Já não estamos aludindo meramente a uma dimensão biológica ou terapêutica no sentido biomédico, associada à saúde, mas a ações realizadas pelos usuários e que não são consideradas como ações de saúde, mas de cuidado. Nessas ações, mobilizam-se não somente os serviços de saúde, mas também a vizinhança. Com essa plasticidade ampliada o cuidado abrange, também, a dimensão política das ações cotidianas do cuidar, sejam dos profissionais ou dos usuários. Seguindo os desenvolvimentos de Joan Tronto, pode-se sustentar que o cuidar ocupa um espaço central na vida humana: "proponho que o conceito de cuidado servirá como a base para repensar os limites morais e, por extensão, o terreno do moral e da vida política" (Tronto, 2009: IOI). A dimensão moral se apresenta na ideia de que o cuidar se relaciona a uma passagem do dilema da autonomia ou dependência para a interdependência humana. Cuidar, para Tronto, implica um engajamento com o outro que conduz a uma percepção-ação (Tronto, 2009: I02). E, finalmente, cuidar não se restringe à dimensão 
individualista ou à diádica, mas envolve os objetos e o entorno onde as ações de cuidar são desenvolvidas e têm uma função social e política na cultura (Tronto, 2009: I03). Nesse sentido, cuidar é uma prática e uma disposição, mas estas duas características variam segundo as situações.

Percebe-se, claramente, como ao associar os itinerários a essa perspectiva sobre o cuidado faz-se necessário um movimento de transversalidade dos campos, já que as práticas de cuidados envolvem dimensões biológicas, psicológicas e culturais interagindo em um mesmo processo.

No que diz respeito à contribuição para o problema da circulação dos usuários pelo sistema de saúde e sua trajetória terapêutica, pode-se salientar que é uma questão que vem acompanhando as ciências sociais que lidam com o processo de saúde e doença há algum tempo. Entretanto, pode-se afirmar também que a produção associada ao conceito de itinerário terapêutico é relativamente recente (Cabral et al., 20I I: 4434).

$\mathrm{Na}$ área da antropologia da saúde, encontramos desenvolvimentos sobre o conceito de itinerários terapêuticos, ora de um ponto de vista mais teórico visando à sua conceitualização como fenômeno complexo carregado de simbolizações múltiplas (Alves \& Souza, I999; Bonet et al., 2009), ora procurando descrever processos de busca de cuidado em contextos específicos, associados a grupos indígenas (Langdon, I994), ou a classes sociais (Gerhardt, 2006; Trad et al., 2010), ou a instituições hospitalares do Sistema de Saúde Pública no Brasil (Pereira, 2008), ou associados a instituições religiosas (Tavares, 20I2). Temos uma vasta produção sobre itinerários terapêuticos realizada no âmbito da saúde coletiva, mas, neste caso, com um interesse voltado para a produção de práticas avaliativas do sistema de saúde que integre a perspectiva do usuário (Costa et al., 2009; Bellato et al., 2009; Gerhardt et al., 2009); e ainda o já citado estudo (Cabral et al., 20II), no qual os autores tentam realizar um mapeamento da produção sobre o tema. ${ }^{\text {10 }}$

O trabalho que pode ser considerado inicial na produção sobre o tema foi produzido por Alves \& Souza (I999); nele, os autores realizam uma síntese de como o conceito de itinerários terapêuticos foi tratado na sociologia da saúde e se preocupam em empreender uma reavaliação da potencialidade teórica desse conceito. É nesta última questão que estou interessado, já que nessa passagem do texto os autores recomendam descer ao nível da experiência, embora sem perder os macroprocessos socioculturais. Ao dirigir a atenção para a experiência vai ficar explícito que os agentes sociais "não se atêm a um único conjunto de estruturas cognitivas, que se possa identificar como a fonte última de significação" (Alves \& Souza, I999: 132); que os itinerários se referem a uma cadeia de eventos sucessivos que formam uma unidade; que itinerário é o "nome que designa um conjunto de planos, estratégias e projetos voltados para um objetivo preconcebido: o tratamento da aflição" (Alves \& Souza, I999: I33); e, finalmente, que os itinerários são construídos 
em um campo de possibilidades problemáticas (Alves \& Souza, I999: 134). Essa visão do itinerário terapêutico como sendo construído em um campo de possibilidades problemáticas nos conduz ao pensamento de que ele não é produto de um plano esquemático e predeterminado, mas de um processo no qual as escolhas são analisadas: "somente no curso da ação [...] é que o individuo começa a interpretar a sua situação, suas ações e o estado de coisas resultante" (Alves \& Souza, I999: I34). Estas escolhas são situacionais e se "encontram impregnadas de interesses, hesitações, incongruências, estratégias e conflitos", já que guardam um caráter "fluido" porque os agentes não se filiam a um modelo interpretativo, mas a uma rede de relações sociais; entretanto, salientam os autores, as redes sociais não são entidades fixas e cristalinas (Alves \& Souza, I999: I35).

Este trabalho se insere, como grande parte da produção da antropologia da saúde, na perspectiva fenomenológica e traz para o centro da reflexão a ideia de experiência e uma reabilitação do mundo sensível (Alves, 2006). Esta perspectiva fenomenológica vai recuperar os modos de estar no mundo dos sujeitos; será fundamental entender as práticas dos sujeitos, a experiência do mundo. E esta experiência do mundo necessariamente nos orienta para a intersubjetividade e para a relação com as coisas no mundo. Como expressa John Law:

se os seres humanos formam uma rede social não é porque eles interagem com outros seres humanos. É porque eles interagem com seres humanos e com outros materiais também [...]. E se esses materiais desaparecessem, então também poderia desaparecer o que chamamos de ordem social (Law, 2003: 3).

Ou seja, as coisas, os objetos também nos agenciam, produzem diferenças; portanto, geram transformações que modificam o curso das ações e dos fluxos nas redes.

Associada à perspectiva pragmática, com essa ênfase nos objetos que conformam as redes, e com um alargamento da concepção de experiência, encontramos uma proposta recente sobre como pensar os itinerários terapêuticos nos trabalhos de Fátima Tavares (20I2). Nos seus estudos sobre a experiência religiosa no candomblé na Bahia, a autora se propõe a trabalhar com os conceitos de acontecimentos e agenciamentos eficazes para refletir sobre os itinerários religiosos, mas a crítica ao conceito pode ser extensiva aos itinerários terapêuticos. Ela parte da ideia de que nos acontecimentos intervêm diversos conectores, tais como corpos, lugares e situações e seres espirituais; esses conectores se "agenciam" mutuamente de modo que, sem núcleos duros e sem fronteiras delimitadas, as experiências religiosas são replicadas em uma multiplicidade de sinais que extrapolam as identidades religiosas (Tavares, 2012: 26I). Para abarcar, então, essa experiência religiosa, o conceito de

itinerário [talvez] não seja o mais adequado, pois toma como a priori a ideia de sujeitos (ainda que porosos e de delimitação flexível) transitando e/ou cons truindo alternativas (o que poderia evocar uma experiência subjetivada). O 
conceito de itinerário encontra-se implicado numa concepção de experiência que confere primazia à contingencialidade, imprevisibilidade e negociação das escolhas efetuadas pelos sujeitos (Tavares, 2012: 263).

Para a autora, ao utilizar a noção de agenciamento, se aposta nas incertezas que se distribuem por todo o processo social, o que nos permitiria tomar distância das intencionalidades dos sujeitos. O foco passaria a estar nas contingencialidades dos agenciamentos locais e coletivos.

Segundo Deleuze \& Parnet, nos agenciamentos há estados de coisas, de corpos, misturas de corpos, ligas, há também enunciados, modos de enunciação, regimes de signos. Nos agenciamentos

\begin{abstract}
os enunciados são sempre coletivos, que põem em jogo, em nós e fora de nós, populações, multiplicidades, territórios, devires, afetos, acontecimentos. O nome próprio não designa um sujeito, mas alguma coisa que se passa ao menos entre dois termos que não são sujeitos, mas agentes, elementos [...]. O escritor inventa agenciamentos a partir de agenciamentos que o inventaram, ele faz passar uma multiplicidade para a outra. O difícil é fazer com que todos os elementos de um conjunto não homogêneo conspirem, fazê-los funcionar juntos (Deleuze \& Parnet, 1998: 65).
\end{abstract}

Deleuze e Guattari, no início do livro Mil platôs dizem: "Escrevemos o Anti-Édipo a dois. Como cada um de nós era vários, já era muita gente” (Deleuze \& Guattari, I995: I I).

Vale perguntar quantos "eus" estão presentes em um encontro de cuidado entre um profissional e um usuário, ou quantos sujeitos estão agenciados em um itinerário de cuidados? Ou isso não faz sentido, porque, quando se fala de agenciamento, esse próprio conceito entra em contradição com a ideia de itinerário e de sujeito? Ao escolher uma perspectiva fenomenológica temos que necessariamente nos ater a um sujeito e à sua vontade, ou esse sujeito que, sem dúvida, está no mundo, é agenciado de forma diferencial pelos outros sujeitos, pelas coisas e pelo ambiente?

Em um artigo interessante, Ricardo Ayres (2004) relata uma experiência da sua prática médica na qual encontra uma paciente que sempre chegava reclamando da espera; Ayres confessa que nesse dia não estava de bom humor, depois de ter trabalhado toda a manhã. Quando a paciente reclamou, ele teve vontade de revidar. Não o fez, mas se surpreendeu por ter pensado nessa possibilidade. Já na consulta, toma a decisão de fechar o prontuário e pede à paciente que fale da sua vida. Depois de superar a desconfiança em relação ao pedido, a mulher descreve a vida com o seu marido, o processo de migração para o Brasil, a construção da casa própria, de forma muito poética. Isto surpreendeu o médico que formara a imagem de uma pessoa sempre reclamando. Ayres concluiu que pela primeira vez tiveram um encontro terapêutico; as mesmas coisas de sempre estavam presentes (prontuário, hipertensão, reclamações, exercícios), mas os novos elementos eram eles dois e 
seu encontro. Mas quem são os que se encontraram? Quais dois? Quantos foram os sujeitos que estavam presentes? A usuária que reclama ou a poeta imigrante, o médico que teve vontade de revidar ou aquele que se surpreende por ter cogitado sobre essa possibilidade? Qual é o agenciamento do prontuário fechado?

Essas reflexões que exponho em relação à consulta relatada por Ricardo Ayres são pertinentes para qualquer itinerário de cuidados. É relevante perguntar-se como se fazem as escolhas e como se tomam as decisões, e, a partir delas, quais são os caminhos que se tornam possíveis, ou seja, que se tornam caminhos. Percebe-se que esses caminhos não preexistem a essas escolhas, nem a esses movimentos, mas eles vão sendo encontrados e caminhados à medida que se tomam essas decisões.

Por isso proponho uma passagem do conceito de itinerários terapêuticos para o de itineração em busca de cuidados. Como disse páginas acima, itineração sugere um movimento ao longo de linhas de vida, um movimento que implica improvisação e criatividade. Improvisar é "seguir os modos do mundo à medida que eles se desenrolam, e não conectar em retrospecto, uma série de pontos já percorridos" (Ingold, 20I2b: 38). Improvisar é juntar-se ao mundo. Assim, as linhas ao longo das quais se vive a vida não preexistem, senão que se criam ao se movimentar pelo mundo; criam-se nesse improvisar. Essa improvisação se dá em um ambiente, que é o que cerca uma coisa; esse ambiente aparece, então, como um emaranhado de linhas entrelaçadas que Ingold chama de malha.

Com as noções de itineração e de malha, configura-se uma perspectiva da movimentação dos usuários mais plástica e mais fluida do que se utilizássemos as de itinerários e de rede. ${ }^{\text {Ir }}$ A ênfase estará distribuída entre os serviços e as itinerações; neles e ao longo deles, porque nessas itinerações encontramos elementos para explicar as escolhas que definirão os próximos passos. No mesmo sentido de ampliação da perspectiva, ao associar as itinerações ao conceito de malha deixamos de pensar em termos de redes que se interpenetram ou que se conectam, e pensamos o sistema de saúde como um ambiente habitado pelos usuários e os profissionais. Assim, já não faria muito sentido falar em "fora" e "dentro" do sistema de saúde quando pensamos nas itinerações dos usuários, porque estas podem levá-lo para um serviço ou para outro, ou para benzedeiras, ou para terapeutas religiosos. Nesse sentido, Alves e Souza se referiam à múltipla adscrição, no artigo comentado anteriormente, quando falavam em hesitações, incongruências e dúvidas na filiação ao modelo interpretativo da doença e, portanto, da atenção e do cuidado. Também a isto se referia Tavares, quando sustenta uma distribuição da agência em uma multiplicidade dos agenciamentos.

Para usar as metáforas de Ingold, os serviços seriam agregados de linhas de vida, sempre abertos, que deixam linhas soltas que se associam com 
outros agregados. Essas linhas são as consequências do trilhar o ambiente, por parte dos sujeitos e das coisas; são condições de possibilidade porque tornam possível que os usuários e os profissionais sejam, que se encontrem, que se relacionem. A imagem que permite visualizar essa malha não seria semelhante a uma rede, mas a um rizoma.

A imagem do rizoma nos dirige novamente à questão da associação entre itinerários, sujeitos e agenciamentos. Como dizem Deleuze \& Guattari (I995), o rizoma se opõe ao modelo da árvore, das raízes. Um rizoma é uma multiplicidade, porque se define por subtração da unidade; entretanto, sempre está presente no rizoma o risco de nascer a árvore, a unidade (por isso não é uma oposição rizoma-árvore). As multiplicidades são rizomáticas e, portanto, não têm sujeito. Para responder à objeção de que essa "multiplicidade reside na pessoa do ator que a projeta no texto" (Deleuze \& Guattari, I995: I6), suas fibras nervosas formam uma trama. Finalmente, para os autores "não existem pontos ou posições num rizoma como se encontra numa estrutura, numa árvore, numa raiz. Existem somente linhas" (Deleuze \& Guattari, I995: I7).

A passagem dos itinerários e dos sistemas para as itinerações e as malhas permite que apareçam os fluxos, as linhas e as multiplicidades. Em outras palavras, permite enfatizar as relações e não as entidades, sejam elas serviços, usuários e profissionais. Cada um deles vai depender de como se agencia com os outros, e assim desenharão malhas diferentes, segundo as improvisações diferenciais que realizem.

Em outro texto desenvolvi a ideia de como nos cotidianos dos serviços se cria uma série de mal-entendidos entre os profissionais, gestores e usuários do sistema de saúde, por uma percepção diferente de como devem ser os itinerários terapêuticos (Bonet, 2013). Se pensarmos em termos de malhas e itinerações em busca de cuidados, as diferentes posições, e os mal-entendidos, se dissipariam em um emaranhado de linhas que é construído por todos na própria movimentação. 
Octavio Bonet é doutor em Antropologia Social pelo Programa de Pós-Graduação em Antropologia Social da Universidade Federal do Rio de Janeiro (PPGAS-UFRJ) e professor adjunto do Departamento de Antropologia Cultural do Instituto de Filosofia e Ciências Sociais da UFRJ (IFCS-UFRJ) e do Programa de PósGraduação em Sociologia e Antropologia da UFRJ (PPGSA-UFRJ). Publicou Saber e sentir. Uma etnografia da aprendizagem da biomedicina (2004); e Os médicos da pessoa. Um olhar antropológico sobre a medicina de família no Brasil e na Argentina (20I4). 


\section{NOTAS}

* Gostaria de agradecer a leitura atenta e as correções sugeridas por Lecticia de Vicenzi Braga.

I Ingold discorda de Bateson em relação à manutenção da única oposição que permanece na obra de Bateson, entre "criatura" e "pleroma", ou entre forma e substância (Ingold, 2000:16).

2 Otávio Velho está se referindo a uma aproximação entre Ingold e as antropologias da América do Sul.

3 É interessante que esse distanciamento de Bateson da antropologia também se relacionava com uma falta de entendimento entre ele e seus colegas ingleses, segundo se depreende da referência que David Lipset faz a uma fala de Edmund Leach: "no ambiente dos trabalhos da antropologia social que se realizava naquele momento em Cambridge não havia ninguém que verdadeiramente entendesse o que Gregory dizia [...] Os conceitos psicológicos e sociológicos que impregnam Naven era uma coisa que ninguém fazia" (Lipset, I991: I60).

4 O segundo movimento poderia ser aquele ensaiado em Making, e os domínios seriam as 4 "as": antropologia, arqueologia, arte e arquitetura.

5 A expressão biopsicossocial é frequentemente utilizada no campo da saúde para denotar aquelas perspectivas que se distanciam do reducionismo biologista da biomedicina, construindo, desse modo, os modelos em disputa, o biomédico e o biopsicossocial (Bonet, 2014; Camargo Jr., I997; Menezes, 2004).

6 Nessa passagem, Ingold critica o paradigma da corporeidade proposto por Csordas, porque não abandonaria a oposição entre cultura e biologia, somente reposicionando o corpo, que antes apareceria do lado da biologia, para o lado da cultura, mas manteria e reforçaria o dualismo cartesiano que dizia pretender desmantelar (Ingold, 2000: 170).

7 A pesquisa sobre a experiência terapêutica no âmbito do Programa Saúde da Família em Juiz de Fora foi realizada junto com Fátima Tavares (UFBA) e uma equipe de bolsistas de iniciação científica. O programa Saúde da família se estrutura em 1994 e atualmente forma o primeiro nível de atenção no Sistema Único de Saúde (SUS) brasileiro; basi- 
camente propõe o atendimento da população através de equipes de saúde formada por médicos, enfermeiros e agentes comunitários de saúde e se fundamenta nos princípios de territorialização, integralidade e continuidade (Bonet, 20I4). A pesquisa contou com financiamento da Fundação de Amparo à Pesquisa de Minas Gerais (FAPEMIG).

8 O sistema formado pelas Clínicas da Família é a implementação do Programa Saúde da Família no Município do Rio de Janeiro. Esta pesquisa conta com o financiamento do Conselho Nacional de Desenvolvimento Científico e Tecnológico (CNPq) e da Fundação de Amparo à Pesquisa do Rio de Janeiro (FAPERJ).

9 Ingold fundamente essa perspectiva em três conceitos: I. Espaço fluido, que colheu de Annemarie Mol e John Law; 2. Mente, de Bateson; e 3. Rizoma, de Deluze e Guattari. Obviamente não seria oportuno desenvolver esses conceitos aqui, mas os estou mencionando porque dão uma ideia de percurso do autor.

Io Devemos salientar que esse artigo se embasa na produção publicada em revistas científicas e não inclui a produção realizada em livros e coletâneas.

I I Em que pese suas diferenças com Ingold, Latour (2006) já defendera uma noção de rede mais plástica, quando disse que a rede "não designa uma coisa que está ali fora e que teria uma forma aproximada de pontos interconectados, como uma rede telefônica, viária ou de esgoto" (Latour, 2006: I89), seria uma "ferramenta que ajuda a descrever alguma coisa, e não algo que se está descrevendo" (Latour, 2006: I90). Ingold faz menção a esta associação quando lembra que, nas primeiras conceituações da teoria ator-rede, as linhas da rede mais do que conectar eram linhas de devir (Ingold 20I2b: 4I). 


\section{REFERÊNCIAS BIBLIOGRÁFICAS}

Alves, Paulo Cesar. (2006). A fenomenologia e as abordagens sistêmicas nos estudos sócio-antropológicos da doença: breve revisão crítica. Caderno de Saúde Pública, 22/8, p. I547-I554.

Alves, Paulo Cesar \& Souza, Iara Maria. (I999). Escolha e avaliação de tratamento para problemas de saúde: considerações sobre o itinerário terapêutico. In: Rabelo, Mirian Cristina, Alves, Paulo Cesar \& Souza, Iara Maria (orgs.). Experiência de doença e narrativa. Rio de Janeiro: Ed. Fiocruz, p. I25-I38.

Ayres, José R. C. M. (2004). O cuidado, os modos de ser (do) humano e as práticas de saúde. Saúde e Sociedade, I3/3, p. I6-29.

Bateson, Gregory. (1989). El mundo del proceso mental. In: Bateson, Gregory \& Bateson, Mary Catherine. El temor de los ángeles. Barcelona: Gedisa. p. 29-42.

Bateson, Gregory. (1982). De la clasificación al proceso. In: Espíritu y naturaleza. Buenos Aires: Amorrortu, p. I69-I82. Bellato, Roseney et al. (2009). Itinerários terapêuticos de famílias e redes para o cuidado na condição crônica: algumas experiências. In: Pinheiro, Roseni \& Martins, Paulo Henrique (orgs.). Avaliação em saúde na perspective do usuário: abordagem multicêntrica. Rio de Janeiro: CEPESC/ IMS-UERJ, p. I87-I94.

Bonet, Octavio Andres Ramon. (2014). Os médicos da pessoa. Um olhar antropológico sobre a medicina de família no Brasil e na Argentina. Rio de Janeiro: 7 Letras.

Bonet, Octavio Andres Ramon. (2013). Malhas de sofrimento nas redes da saúde. Ciência Hoje, 52, p. 22-25.

Bonet, Octavio \& Tavares, Fátima. (2006). Redes em redes: dimensões intersticiais no sistema de cuidados à saúde. In: Pinheiro, Roseni \& Mattos, Ruben (orgs.). Gestão em redes. Práticas de avaliação, formação e participação na saúde. Rio de Janeiro: CEPESC, p. 385-400.

Bonet, Octavio et al. (2009). Situação-centrada, rede e itinerário terapêutico: o trabalho dos mediadores. In: Pinheiro, Roseni \& Martins, Paulo Henrique (orgs.). Avaliação em saúde na perspectiva do usuário: abordagem multicêntrica. Rio de Janeiro: CEPESC/IMS-UERJ, p. 24I-250. 
Bonet, Octavio \& Tavares, Fátima. (2007). O cuidado como metáfora nas redes de prática terapêutica. In: Pinheiro, Roseni \& Mattos, Ruben (orgs.). Razões públicas para a integralidade em saúde: o cuidado como valor. Rio de Janeiro: CEPESC, p. 263-278.

Cabral, Ana Lucia L. V. et al. (20II). Itinerários terapêuticos: o estado da arte da produção científica no Brasil. Ciência \& Saúde Coletiva, I6/II, p. 4433-4442.

Camargo Jr., K. R. (I997). A biomedicina. Physis. Revista de Saúde Coletiva, 7/I, p. 45-69.

Costa, Aldeman L. R. da et al. (2009). O percurso na construção dos itinerários terapêuticos de familias e redes para o cuidado. In: Pinheiro, Roseni \& Martins, Paulo Henrique (orgs.). Avaliação em saúde na perspectiva do usuário: abordagem multicêntrica. Rio de Janeiro: CEPESC/IMS-UERJ, p. I95-202.

Deleuze, Gilles \& Parnet, Claire. (I998). Diálogos. São Paulo: Escuta.

Deleuze, Gilles \& Guattari, Felix. (I995). "Introdução: Rizoma". In: Mil Platôs. Capitalismo e esquizofrenia. Rio de Janeiro: Ed. 34, p. II- 37.

Gerhardt, Tatiana Engel. (2006). Itinerários terapêuticos em situação de pobreza: diversidade e pluralidade. Cadernos de Saúde Pública, 22, p. 2449-2463.

Gerhardt, Tatiana Engel et al. (2009). Determinantes sociais e práticas avaliativas de integralidade em saúde: pensando a situação de adoecimento crônico em um contexto rural. In: Pinheiro, Roseni \& Martins, Paulo Henrique (orgs.). Avaliação em saúde na perspectiva do usuário: abordagem multicêntrica. Rio de Janeiro: CEPESC/IMS-UERJ, p. 287-298.

Harries-Jones, Peter. (I995). A recursive vision: ecological understanding and Gregory Bateson. Toronto: University of Toronto Press.

Ingold, Tim. (2013). Making: anthropology, archaeology, art and architecture. Londres: Routledge.

Ingold, Tim. (2012). Ambientes para la vida. Coversaciones sobre humanidad, conocimiento e antropología. Montevideo: Trilce.

Ingold, Tim. (20I2b). Trazendo as coisas de volta à vida: Emaranhados criativos num mundo de materiais. Horizontes Antropológicos, 37, p. 25- 44. 
Ingold, Tim. (20II). Being alive: essays on movement, knowledge and description. Londres: Routledge.

Ingold, Tim. (2008). Tres en uno: cómo disolver las distinciones entre mente, cuerpo y cultura. In: Sánchez-Criado, Tomás (org.). Tecnogénesis. La construcción técnica de las ecologías humanas (vol. 2). Madrid: AIBR, p. I-33.

Ingold, Tim. (200I). From complementarity to obviation: on dissolving the boundaries between social and biological anthropology, archaeology, and psychology. In: Oyama, Susan, Griffiths, Paul E. \& Gray, Russell D. (orgs). Cycles of contingency. Developmental systems and evolution. Massachusetts: The MIT Press, p. 255-279.

Ingold, Tim. (2000). The perception of the enviroment. Essays on livelihood, dwelling and skill. Londres: Routledge.

Langdon, Esther Jean. (I994). Representações de doenças e itinerário terapêutico dos Siona da Amazônia colombiana. In: Santos, Ricardo \& Coimbra Junior, Carlos (orgs.). Saúde e povos indígenas. Rio de Janeiro: Fiocruz, p.II5-42.

Latour, Bruno. (2006). Changer de société. Refaire de la sociologie. Paris: Éditions la Découverte.

Law, John. (2003). After ANT: complexity, naming and topology. In: Law, John \& Hassard, John (orgs.). Actor network theory and after. Oxford: Wiley-Blackwell, p. I-I4.

Lipset, David. (I99I). Gregory Bateson. El legado de un hombre de ciencia. México: Fondo de Cultura Económica.

Mauss, Marcel. (2003). As técnicas do corpo. In: Sociologia e antropologia. São Paulo: Cosac Naify, p. 40I-422.

Mauss, Marcel. (2003b). Efeito físico no indivíduo da ideia de morte sugerida pela coletividade (Austrália, Nova Zelândia). In: Sociologia e Antropologia. São Paulo: Cosac Naify, p. 349-365.

Mauss, Marcel. (200I). A expressão obrigatória dos sentimentos. In: Ensaios de Sociologia. São Paulo: Perspectiva, p. 325-335.

Menezes, Rachel Aisengart. (2004). Em busca da boa morte: antropologia dos cuidados paliativos. Rio de Janeiro: Fiocruz/ Garamond. 
Pereira, Diogo N. (2008). Itinerários terapêuticos entre pacientes do Hospital de Base (DF). Dissertação de Mestrado em Antropologia Social, Universidade de Brasília.

Tavares, Fátima. (2012). Experiência religiosa e agenciamentos eficazes. In: Tavares, Fátima \& Bassi, Francesca (orgs.). Para além da eficácia simbólica. Estudos em ritual, religião e saúde. Salvador: EDUBA, p. 26I- 282.

Trad, Leny Alves Bonfim et al. (20I0). Itinerários terapêuticos face à hipertensão arterial em famílias de classe popular. Cadernos de Saúde Pública, 26/4, p. 797-806.

Tronto, Joan. (1993). Moral boundaries: a political argument for an ethic of care. Londres: Routledge.

Velho, Otávio. (2013). Epílogo. Papeles de Trabajo, 7/II, p. IO9-II2.

Velho, Otávio. (200I). De Bateson a Ingold: passos na constituição de um paradigma ecológico. Mana, 7/2, p. I33-I40. 


\section{ITINERAÇÕES E MALHAS PARA PENSAR OS ITINERÁRIOS DE CUIDADO. A PROPÓSITO DE TIM INGOLD}

Resumo

O objetivo do artigo é propor uma perspectiva diferente para analisar os itinerários de cuidados terapêuticos utilizando os conceitos de itineração e malha, extraídos da obra de Tim Ingold. Para tal objetivo é necessário realizar uma revisão dos conceitos e da perspectiva relacional proposta por Tim Ingold, que começa pelas concepções de obviação e da transversalidade dos campos para chegar à de itineração e dos emaranhados de linhas de vida. Não se pretende dar conta da obra de Ingold, mas utilizar alguns conceitos que permitam lançar nova luz sobre a questão dos itinerários terapêuticos.

\section{ITINERATION AND MESHWORK TO RETHINK THERAPEUTIC ITINERARIES. ON TIM INGOLD}

The purpose of the article is to suggest a different perspective from which to analyze itineraries of therapeutic care, using the concepts of itineration and meshwork, taken from the work of Tim Ingold. To do so, it is necessary to review Ingold's concepts and his relational perspective, beginning with the notions of obviation and transversality of fields, as well as itineration and meshworks of entangled lines of life. The aim of the article is not to do full justice to Ingold's thought, but rather to use some of his concepts that may bring new light to the question of therapeutic itineraries.

\section{Palavras-chave}

Itinerários terapêuticos;

Cuidado;

Itineração;

Linhas de vida;

Tim Ingold.

\section{Keywords}

Therapeutic itineraries;

Care;

Itineration;

Entangled lines of life;

Tim Ingold. 